DOI: 10.17707/AgricultForest.62.3.11

\title{
Radovan ĐUROVIĆ and Gojko R. NIKOLIĆ \\ ASPECTS OF URBAN AND RURAL LAND CONSOLIDATION AND ACCURACY PROBLEMS OF GIS DATABASE FOR THE NEEDS OF SPATIAL PLANNING DOCUMENTS
}

\begin{abstract}
SUMMARY
Spatial development of urban and rural areas is a priority task in an adequate urban land management of all modern societies. Although provided by the Law on Agricultural Land, unfortunately such measures are not implemented in Montenegro. One of the main problems is in unresolved legal property relations as well as in the out of date existing cadastral records. A cadastral record is a variable category that should be adjusted to the current situation through the maintaining process. Practice has shown that the rights holders do not report timely a large number of changes of the registered status in the cadastre to the administrative authority.

A particular problem is disagreement of surfaces in graphic and alphanumeric GIS database, but all that together affects big problems when adopting the cadastral maps as conditionally accurate on the development and implementation of detailed urban plans. Problem persists in operational cadastre on the entire territory of Montenegro, and its genesis and way of resolving it are specifically analysed in examples in the Municipality of Bar.
\end{abstract}

Keywords: land consolidation, cadastral maps, detailed urban plan, property title, GIS, database, DKP Bar.

\section{INTRODUCTION}

Operational cadastre represents a complete documentation of public and private rights and restrictions for users and land owners, which is based on state surveying (Kaufmann and Steudler, 1998). Its statement is geodetic and cadastral information system with a database in which the land registration and cadastral mapping are aligned. Also, human beings and activities of a society in the geographic space are at the same time both a problem and systematic solution for sustainable development.

Some of the challenges faced today have a critical geographic dimensionespecially when it comes to natural disasters, climate changes or the process of urbanization. The catastrophic earthquake that took place on 15th of April 1979 and the consequences left on the area Montenegrin coast, especially in the Municipality of Bar, imposed the need to use the survey data with greater

\footnotetext{
1 Radovan ĐUROVIĆ, (corresponding author: zlatko1979@yahoo.com), Faculty of Civil Engineering University of Montenegro, Podgorica, MONTENEGRO, Gojko R. NIKOLIĆ, Institute of Geography Nikšić, University of Montenegro, MONTENEGRO.

Notes: The authors declare that they have no conflicts of interest. Authorship Form signed online.
} 
accuracy and more homogenously. The characteristic found in Bar is that it had a major disagreement of the points of geodetic networks between each other. To understand the etiology and exploratory nature of this problem, it is necessary to explain theoretical and practical base of the city trigonometric networks.

Territory of Montenegro with 1382623 hectares is divided into 23 political and 796 cadastral municipalities, and according to the cadastral record data, there are about 1300000 cadastral plots. The major problem shown in practice is quality of the existing documentation which is to be used in new surveying. Namely, in the most cadastral municipalities for which the surveying is to be done, there has been into force the listed cadastre which is used mainly for fiscal purposes and only for calculation of cadastral income. Value and quality of property record established in such way are limited on multiple grounds, especially in rural areas.

Agriculture is an activity that has high economic potential for the Municipality of Bar- arable land includes about 5.551 hectare. From the point of geo-ecological conditions in the existing spatial planning documentation (GUP Bar 6.118.58 ha) two parts are clearly separated: narrow coastal area (indented seashore with a significant number of larger and smaller bays and capes) and mountain ranges of Rumija, Lisinja and Sutorman. The spatial statement of geoecological resources within the analysed documents is resumed to: optimal climate of sea and lake (Skadar Lake) shore, its distinctive morphology (46 km) with unique beaches, extreme wealth of biodiversity, appealing environment of old and new urban settlements. The existing documentation recognizes area of Bar as one of the three areas of intensive agriculture: the total area of olive trees complex is 477.7 ha (nearly 110000 trees), which are located in the areas around the fast traffic road; the total area of other agricultural land (around 100000 citrus trees, orchards 2217 ha, vineyards 245 ha, field crops, etc.) is 826.81ha. Particular problem is that these areas are mostly within the mixed space intended for housing and work (the area below the existing railway plants and the main road up to Gorak, part of Polja, Čeluga, Tomba, Zaljevo as well as Pečurica and Kunje).

For many years Montenegro is facing the issue of constructing objects of various types, surface and purpose, which are in contrary to the positive legislation of Montenegro which regulates this field. There is an established term "informal" construction for such phenomena. It is a construction without a building permit or without the required legal and technical documentation, which in the long term permanently changes and destroys the space and directly reduces both current and future development opportunities. Illegal construction has recently taken hold in huge proportions, thus creating big problems in terms of public utility, transportation, hygiene and environment, organization and legal property relations. In the future, in these areas it is necessary to resolve all problems in technical, economic and legally rational and feasible way.

Number of constructions built contrary to regulations is measured by tens of thousands. The field of spatial development and construction in Montenegrin 
legal system is regulated by the Law on Spatial Planning and Construction ("Official Gazette of Montenegro", no. 51/08, 40/10, 34/11, 40/11 and 47/11), which does not provide specific procedure when it comes to development of planning documents that are used for integration of constructions built without building permits - since the issue has been resolved systematically. In the process of developing the planning documents, full attention is unquestionably dedicated to constructions built without a building permit. Vienna Declaration on Informal Settlements in South Eastern Europe, which Montenegro signed in September 2004, envisages that signatory countries aim at the complete regional resolution of informal settlements by the year 2015 and signatories shall undertake in-situ regularization and upgrading to the maximum extent.

The old Law on Construction Land ("Official Gazette of Montenegro" no. 28/80 and 12/86) did not recognize the ownership in the construction zone. In fact, natural and legal entities could have had the right to manage, use or permanently use and dispose the land in the social ownership and now it is a state property as long as the state is the owner. It was only when the new Law on Construction Land has been adopted ("Official Gazette of RM" no. 55/00) and the Law on Ownership and Legal Relations ("Official Gazette of RM", no. 19/09) with the Article 419 that this right is transferred into ownership right. However, this change of the right is not made ex officio, but at the request of the party. Attempts to abuse this right are often. Namely, many natural persons in the second half of the last century, when the recordings for real estate cadastre were done, registered the state property for their use and more recently tried to transfer it into their ownership. Many took advantage of that interim period and sold land for which they had only the right to use it and only the adoption of the Law on Ownership and Legal Relations led to determination of these abuses.

\section{MATERIAL AND METHODS}

In this paper we define these problems and we used the results within the case study which has been done on the example of cadastral records of Bar. The study in spatial terms covers also parts of the rural area of municipality. The analysis includes its geo-ecological problems, particularly those related to agricultural land.

With the analysis we have covered both the planning documentation and targeted field observations along with geodetic and cadastral information system with a database, which confirmed the existence of so-called the primary problems in this area: along with those related to conversion and endangered land, there is also its visible fragmentation especially due to the construction of family houses and cottages.

The next big problem is disputable cadastral records and inaccuracies in the existing GIS database, which cumulatively creates problems in development and implementation of urban plans and compromises their application in practice.

With modern GIS tools all problems become visible when using imprecise old cadastral maps and databases: with digitizing and georeferencing plans of old 
graphic surveying, the problem is that such substrates are often useless in overlapping with ODK or DOF, along with the out of date cadastre and disagreement of cultures in the cadastre with the ones on the ground. Many cadastral plots are converted and registered under a different culture. It is often the case that the same plot has one data or culture in cadastral record and different one in the land registry.

That is the reason why we offered concrete proposals, which are based on previous results and/or experiences from ex YU region, and we provided original solutions with a highlighted explorative character. Also, possibilities of implementing consolidation projects have been considered.

\section{Urban and rural land consolidation with possible application in Montenegro}

Land is limited and most valuable resource on disposal to the mankind. With this in mind, it is clear that land management has a very important role in development of mankind and that the existence of an efficient system of land management is necessary condition for development of each country. Although the land management always has had high importance, it seems that such importance has never been greater than in modern times because of the rapid urbanization that is taking place in all countries of the world, though not at the same time (Šoškić, 2016).

Land consolidation (in Dutch: ruilverkaveling; in French: remembrement; in German: Flurbereinigung) means "a comprehensive procedure of deploying existing rural areas with fragmented agricultural or forest landholdings or their parts" (Vitikainen, 2004). It can be defined as the agrarian-technical operation which represents socio-economic and political measure, and which aims to group and encompass land properties in order to provide optimum conditions for profitable production (Lukic, 1977). Along with grouping and creating plots with proper shape, land consolidation increases the surface of productive land, reduces processing costs, creates conditions for expansion of commodity production, creates favourable conditions for association of farmers, carries out rationalization and construction of road and drainage network and provides basis for urbanization of settlements.

First land consolidations are known in Italy as early as in XIV century, then Keptan in south eastern Bavaria in the mid of XVI century. The first land consolidation in the former Yugoslavia when a settlement was planned took place (subdivision) in Tornjoš, a small settlement during consolidation of Municipality of Senta (1963-1966).

Taking into account the way of using and population of the area where it is done, the rough distinction could be made between rural and urban land consolidation.

Rural land consolidation is used as a synonym for integrated rural development, although it is common for this expression to represent an outdated type of agricultural structural development. Integrated rural development is generally referred to the development of rural areas. "Between the land 
consolidation and spatial planning as a measure for spatial development, there must be a connection as required by the legislation. The question is what are such connections, whether the spatial plans provide a solid basis for development of land consolidation project and to which extent the items of spatial plans can be achieved through the process of land consolidation? Problems arise when a certain part of space is not "covered" with spatial or urban plan and then within such space the territory is used and developed spontaneously. If a territory is not covered by such plans, then on the margins of the construction zone of the planned settlement the population can spontaneously settle without the threat that their residential and other buildings could be later demolished "(Trifkovic, 2001). In such cases, the geodetic experts leading the land consolidation are given the difficult task to practically legalize the existing situation within the spatial development of construction zone.

"The most effective way of land consolidation of rural development is a comprehensive land consolidation, but in some cases other approaches such as simplified land consolidation, voluntary group land consolidation and individual initiative for land consolidation can bring a benefit" (Čvorić, 2011).

The land consolidation project provides also a project of planning and reconstructing the rural settlement and the land for the common needs of the settlement is allocated, by adopting a common coefficient of reduction for all participants in land consolidation, in a way which takes from each owner a land in proportion to his/her possession.

FAO (Land Tenure Studies 6, 2003) recommendations for improvement of rural areas are "good practices" for countries in transition. One of important European positions is to reduce the gaps between rural and urban areas through improvement of situation in the villages. The range of objectives of land consolidation in rural development is very broad, starting from agricultural development to reconstruction of villages and protection and improvement of environment. Land consolidation can be used as a very efficient instrument and a starting point of rural development so the landowners have more opportunities for improvement of their situation.

Urban land consolidation as an instrument for development of construction land has been used in Western Europe for more than a century. In recent decades urban land consolidation is used in many developed countries as well as in developing countries worldwide. It relies on the spatial or urban plan of the observed area and usually is an instrument for their implementation. It develops land in modern way that all participants have interest in. A land achieves significantly higher market value through its conversion from agricultural land into construction land. In such process a new cadastre record and land register are established, on the basis of exposing the data on surveying and ownership to the public.

Larsson (Larsson, 1997) lists a number of ways for implementing measures of urban planning. The first one is to adopt a new urban plan and to wait its realization through the usual procedures, over time. This requires a lot of 
time, but also problems arise in coordinating its implementation. Another way is to purchase the entire land of the territory plan by a single owner, whether it to be one private or public entity or a state institution. This process is very expensive and also requires a longer period of time. The third way is urban land consolidation, which is being increasingly applied in recent times. It is an organized method that has a formal organization. In this process, the structure of land boundaries is to be changed but the land owners are not changed. Urban land consolidation in a number of countries in the world is increasingly used as an instrument for implementation of measures for urban development. The process of urban development can be described in three main phases which include planning, land development and construction of infrastructure. Urban land consolidation is classified as a stage of land management although, in certain cases, it can be a part of the planning phase which includes development of spacial and urban plans.

In Montenegro, the land consolidation has been carried out on the basis of the Law on Agricultural Land ("Official Gazette of Montenegro", No.15/92, 59/92 and 27/94). Work's program on developing agricultural territory through land consolidation refers to works that are envisaged by the Strategy for Development of Food Production and Rural Areas.

Montenegro does not have a lot of large agricultural areas at the same complex. The plots are small and fragmented and in such conditions, the production costs are high which increases a sales price. Production in difficult natural conditions on very fragmented property does not enable stronger modernization, which causes low competitiveness. It is even worse that there is no legislation which would prevent further property fragmentation. There is a big problem in conversion of purpose of agricultural land, by which this nonrenewable resource is permanently lost. Also, one of the main problems for adoption of such measures is in unresolved legal property relations as well as the out of date and inaccurate existing cadastral records. There is a characteristic example in the attempt of implementing such project in Mrčevo Polje and Grbalj behind the beach Jaz, where after trying to determine the factual situation the project was stopped. We are witnesses that these unresolved relations still persist on this attractive territory.

The total area of agricultural land in 2012, according to MONSTAT data was 515,717 hectares, which represents 37.34 percent of total territory of Montenegro, out of which 190,000 hectares are cultivated. Statistical data focus our attention in two levels: first, it points out that if we look at the total agricultural land, Montenegro has valuable and rich resource - $0.82 \mathrm{ha} /$ per capita. However, if we reduce it to the category of arable land, this value is significantly lower - 0.30 ha / per capita. If we follow the methodology of EU countries, which in the category of arable land does not include meadows, then this geoecological potential at the level of Montenegro is very law -0.009 ha / per capita and thus very sensitive and endangered. This level focuses our attention to physical, chemical and biological degradation of agricultural land, including pollution. A 
particular problem is conversion and "consumption" of land for urbanization, roads, industrial and other facilities. This resource in municipalities of Montenegrin coast is particularly threatened and its protection, optimal and sustainable management involves primarily the existence of valid and practically operational GIS database records on immovable property.

In the period from 1998 to 2002, the works on agricultural land consolidation were carried out only on the territory of Municipalities of Ulcinj on the area of 100 ha and Municipality of Herceg Novi (Sutorinsko Polje and Bračkovina) on the area of about 120 ha. This program included a plan on developing an agricultural land consolidation on the area of about 240 ha in Municipalities of Budva and Kotor (Mrčevo).

So far in Montenegro urban land consolidation has not been applied for construction land development, at least not in a form and a manner in which all of its potentials would be used. The urban land consolidation is the easiest way of providing necessary land for public space, infrastructure facilities and other public purposes, without which any development of settlement is unimaginable. Providing a land for common needs is not possible without reducing the surface of property of participants in urban land consolidation. On the other hand, this is a way which the land not suitable for construction converts into the land suitable for construction and its market value increases significantly which compensates to participants the loss of a certain part of the property.

Among many effects it is important to resolve and manage all legal property relations among the participants of land consolidation. It is indisputable fact that actual situation on the ground in a large percentage is not in line with the status that is registered in the land cadastre records and land registry. There are many effects that would be achieved with the land consolidation projects but unfortunately the budget or any announced investments do not mention them. Perhaps a model of public-private partnership would be a good way in which the private sector and the state could find common ground. However there are many problems which are obstacles to starting these processes as well as in adopting the very urban plans and hereinafter only some of them will be described.

\section{Updated cadastral maps and use of the existing GIS database}

Operability and importance of new IC technologies in geodetic and cadastral records of urban units, is the fact that changes the way and dynamics of its use. GIS with a database is the "fuel" that accelerates these changes, especially in developing digital maps and their database, in dynamics of inserting the changes and in the way of maintaining a modern cadastre (Longley et al., 2005).

On the other hand, flows of data manipulation in cadastral record impose the need for distributing spatial information to a wide range of users. User requirements relate to the review and research of data in the form of maps, to the search for list of entity attributes according to certain criteria, to the control of displaying layers and finally, to generating appropriate reports and/or basis. 
When it comes to advanced users of these technologies, it is primarily about creating physical and logical data model for spatial information with integration of available data, and creating the appropriate topology and data analysis. At the state and local level advanced software systems are mainly used for managing spatial data through ESRI ArcGIS architecture (ArcExplorer, ArcMap, ArcCatalog, ArcPad), where the data can be manipulated from a local computer or as clients with a full functionality with the request to use GIS data from remote server over the Internet. For clients with full functionality, most of the operations related to manipulation of spatial data take place on the client's side, where the role of server is to make available the shared information. ESRI ArcIMS is used for distribution of maps, data and meta-data via the Internet. The system is designed for easy creation of maps, for development of web pages with interactive maps and for administration of WEB-GIS sites. The architecture of ArcIMS refers to the presentation, the level of business logic and data level.

The database of agricultural land is based on: legal frames and Development Strategy for Food Production and Rural Areas, GIS-oriented information system which is expressed through the alphanumeric and graphic cadastral data and DOF, and the data related to records, mode of use and management. It can be modularly upgraded; it allows control of the collected data and assignment of attributes based on the spatial relations between geometric objects. Its ultimate goal is to know the status i.e. sustainable management of each cadastral plot.

Cadastral municipality is a territorial unit that as a rule covers an area of inhabited settlement, which has the statutory name and which represents the basic unit where surveying is performed and real estate cadastre is made. Administration body establishes borders of cadastral municipality, by placing geodetic marks and describing borders in the borders record book (National Assembly of the Republic of Montenegro (2007).

\section{RESULTS AND DISCUSSION}

In the Municipality of Bar there have been a number of cases in which during the establishment of the land cadastre in 1974, the registration of the right to use was carried out without any legal basis, and in the archives of the cadastre of the period there are only lists that cannot be taken as proof of ownership. Therefore, when establishing the Real Estate Cadastre the previous entry should have been taken as a record of the property at that time and there should have been an obligatory request for the legal basis for acquisition through exposure of data to public and establishment of actual rights on real estate.

Previous realisations of urban plans consisted of designing and determining the boundaries of construction plot in which, in most cases, the existing parcelling did not match the new projected boundaries or the rules important for construction and public needs. Thus during the establishment, the new building plots usually consist of parts of the existing cadastral plots that belong to different owners, which in practice very often presents insurmountable 
obstacles for resolving ownership and legal relations. The end result is that the construction plot is to belong to one entity, which would later get the right to build on it. The conflict between designed situation and ownership situation is supported with the emergence of incompliance between the boundaries of using the land in the field and the actual legal status of plots boundaries in the real estate cadastre.

The surfaces of cadastre plots are determined in different ways: from the original measure, from the measures taken graphically from cadastral map, from the coordinates of detailed points of cadastre plots from cadastre maps or by planimetry - an instrument for mechanical calculation of surface.

In practice, we meet a number of examples in which the difference between the surface of plot registered in the property title and the surface that is obtained from the coordinates of detailed points of cadastral map is bigger than the allowed value that is obtained by the formula (Rulebook on content and method for state survey of immovable properties, draft version, 2015):

$$
\Delta=0.0007 * \sqrt{P} * M
$$

where $\mathrm{M}$ is the denominator of the plan scale and $\mathrm{P}$ is the plot surface.

Example 1: The difference between the plot surface in property title and cadastral map

Cadastral plot no. 4386/1 KO Novi Bar from the property title number 1173, which is located within the plan that was developed in the scale of 1: 1000. The surface registered in the property title is $310 \mathrm{~m}^{2}$. When the surface area is calculated from the coordinates of the turning points, than the following is obtained $\mathrm{P}=202 \mathrm{~m}^{2}$. That plot has approximately $35 \%$ less surface on the map and at the same time it is the surface that could be marked on the ground.

The difference in the surface value is in this case $108 \mathrm{~m}^{2}$, which means that the potential buyer could be mistaken when purchasing a plot, i.e. the person could pay the sum as for $310 \mathrm{~m}^{2}$, although in fact $108 \mathrm{~m}^{2}$ do not exist, having in mind that the legal transactions are based on data from the cadastral documentation in accordance with the principle of trust in the real estate cadastre. According to this principle, a conscientious right obtainer can rely on credibility of what is written, which means truthfulness and completeness. Usually the parties are familiar with these "problems in Cadastre" and in a purchase contract (as it must be linked to data from property title) the surface from the numerics is stated but in fact the real price comes down to what the plot contains on the field.

The consequence of this problem is also in spatial planning where for the needs of calculating urbanistic parameters (urbanistic potentials) there are used and exclusively taken as the reference value those surfaces registered in the cadastral records.

Proposal for solution: a solution to this problem has a legal and geodetic aspect. From the geodetic aspect it is possible to survey the site and determine whether the boundaries on the field correspond to the boundaries in the cadastral map and in that case it would be possible to carry out a correction of surface in property title. However, from a legal point of view changes in the surface require 
a legal basis. If, for example is taken the case where the purchase contract is a legal basis of registered owner, that owner could with the previous owner conclude an annex to the contract which would state the exact surface from the plan but the limitation is in the rule that the seller cannot transfer more rights to the buyer than those rights possessed by the very seller. Usually, in practice the predecessor after selling a real estate is not interested in the problems of followers, so these annexes are difficult to obtain. In addition, the surface which is registered in the property title represents the basis for calculating property tax, property transfer tax, etc. One solution is for the Real Estate Administration to adopt an act that would implement a surface from the map and the field through the property title. There should be defined an "Elaborate on Compliance of Surfaces" which are calculated in the previous period and surface areas from the coordinates without changing geometry of plots. Such elaborate would have multiple usages in the process of corrections in the real estate cadastre, in issuing urbanistic and technical conditions and building permits, etc.

In addition to errors in the procedure of establishing a real estate cadastre and cadastral maps at certain locations there are wrong positions of boundaries of cadastral plots due to non-compliance with regulation in the process of maintaining the real estate cadastre when primarily the parcelling of cadastral plots was done on the basis of measurements of fronts (Djurovic, 2011).

The cadastral map is developed on the basis of aero-photogrammetric surveying where the owners were required to lawfully mark the boundaries of their plots.

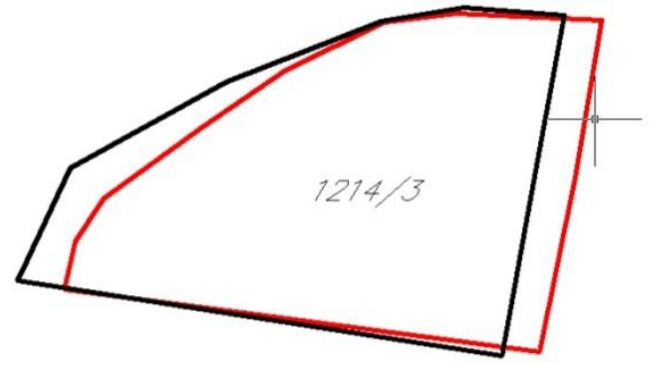

Figure 1. Example of problem in reconstruction of boundaries

Example 2: Cadastral plot no. 1214/3 KO Mišići, the Municipality of Bar. Black colour shows a cadastral plot and red colour shows the position of plot obtained on the basis of surveying the existing boundaries on the spot. Obviously this is a translational displacement. When in such case the boundaries of the parcel on the ground should be marked based on the coordinates from cadastral map, the absurd situation arises in which the spot on the ground is marked with $2-3 \mathrm{~m}$ of distance compared to the existing border based on which the boundary is established in cadastre.

Proposal for solution: to determine the age of the boundary i.e. whether the boundary was established before the aero-photogrammetric surveying. If so, and during the presentation of the surveying data to public and during the registration 
of the right no complaints from the neighbours were submitted, a border that is on the ground should be adopted through the procedure of planning the borders.

Example 3: A concrete example of disagreement of boundaries of cadastre plot in relation to their actual position on the ground

At the same site there is an example in which the position of the road is completely misrepresented on the cadastral map so that when its position is marked on the ground it "goes" over the existing facilities and the road really exists on the ground but it is in fact located behind the facility on its northeast side.

After the surveying, there were decrypted on photo plans and marked the details and the boundaries of plots and the cultures and facilities were drawn. In this procedure, which consists of several phases the errors occur which results in the mapping of the details in wrong position. On the other side, the obvious flaw of boundaries in the real estate cadastre should be able to get re-transferred at any time to the field through professional cadastral surveying with reasonable accuracy which means that the borders can be reproduced on the site (field). This return transfer of established boundaries is carried out within the framework of marking the boundaries of the plots.

Figure 2 shows the position of cadastral plot no. 825/171 KO Šušanj where the blue line is the actual position on the basis of surveying with polar method on the ground and the black line is position on the cadastral map. On the north-east side of the plot there is a road which according to the cadastral map "goes" over the recorded existing facilities.

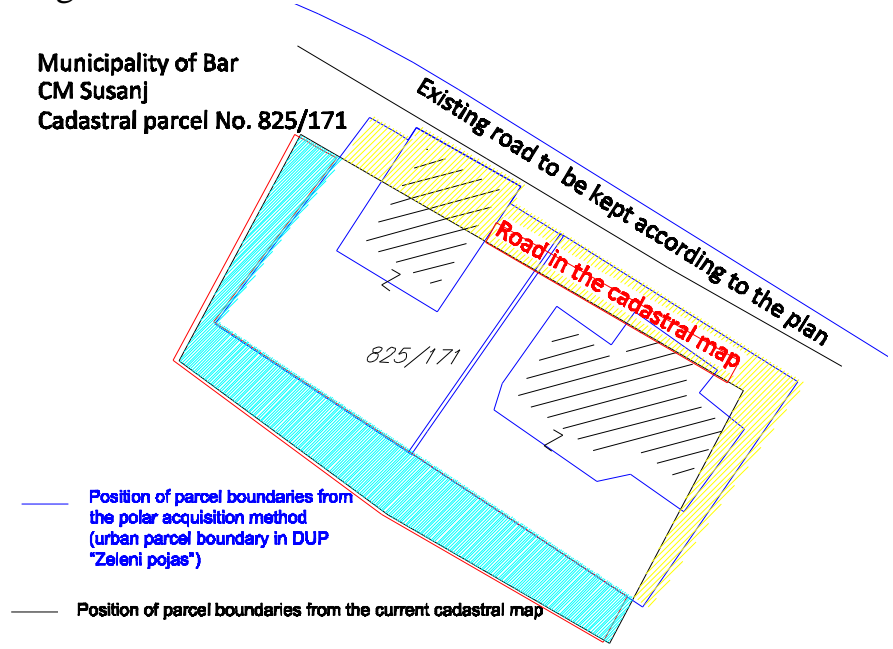

Figure 2. Overview of boundaries of cadastral plot no. 825/171 KO Šušanj.

Proposal for solution: Based on the position of the existing borders of immovable property on the field and the position of boundaries of cadastral plot no. 825/141 on the cadastral map there can be concluded that the property owner keeps on the ground a yellow hatched area within the property and that the owner is not registered as the holder of the property but according to the cadastral data it 
represents a fraction of non-categorized road (although in fact the road is located above the presented position) while the area which is hatched in green is beyond the fence of the owner's property although in the cadastral register the owner is registered as holder of the right on ownership on that part of the plot.

Accepting the cadastral boundaries as conditionally accurate and by planning the road on the position shown on the cadastral map we would come into a situation that the road paves the way over the existing facilities and such facilities could not be registered in the cadastre. Given that these discrepancies of boundaries of immovable property are not the result of shift in boundaries and occupation on the field, but are result of incorrect mapping on the cadastral map, there would be a great harm to owners of real estate that is not caused by their fault but by the work of state bodies. For these reasons there is a necessity to check GIS database and for accurate and precise determination of the current situation before development of planning documents in order to avoid problems in implementation of the plan.

Based on the given examples we can conclude that the position of boundaries of cadastral plots which are shown on the cadastral map cannot be accepted as a priori true but there is a need to provide for development of detailed urban plans a quality and updated geodetic basis but in practice, usually due to the lack of funds we stick to alternative solutions and use the existing cadastral and topographic maps as well as the data gathered by authorized geodetic organizations in the process of maintaining the real estate cadastre.

\section{CONCLUSIONS}

Agricultural land consolidation increases the income from agriculture and simultaneously creates material and social conditions for improvement of socioeconomic conditions in rural areas, as well as for overcoming negative interpersonal relationships arising from disputes over land. Although most of the rural territory of Montenegro with its geomorphological characteristics is not the most favourable for implementation of these projects in typical form, for this neglected part there should be found one of already applied models from developed countries.

Increasing urbanization, if not accompanied by appropriate mechanisms for development of urban land, can cause a number of problems. One of the biggest problems is the provision of land for public purposes (streets, green surfaces, parks, kindergartens, schools, health institution, etc.). Another problem is provision of appropriate structures of plots (shape, size, position) in accordance with their intended purpose. From the above mentioned, it can be concluded that it is necessary to develop urban land management system that will effectively resolve all of these problems (Šoškić, 2016).

Out of major issues and projects that are waiting in the near future, the inevitable one is the problem of illegally constructed buildings which according to some estimates are in the amount over 100000 in Montenegro and are mainly concentrated in small and medium-sized settlements around urban areas. It is an 
unofficial data arising from the fact that significant number of informal constructions is not registered in the real estate cadastre, i.e. there are much more of them than shown by the official data.

The greatest challenges faced today have a critical geographic dimensionespecially when it comes to natural disasters, climate change or uncontrolled urbanization process. Disadvantages of cadastral records and inaccuracies in the existing GIS databases, which are described in this paper as causes to the problems in development and implementation of urban plans, can be divided into three categories: the out of date cadastral data, which is reflected in great number of changes that have occurred among real estates on the field and which are not recorded at the cadastral map and cadastral records; inaccuracy in boundaries positions of cadastral plots and in topographic details as well as difference of surfaces registered in property title and surfaces that are obtained by calculations from the cadastral map.

Operability and the importance of new IC technologies in geodetic and cadastral urban complexes is the fact that changes the way and dynamics of its use. GIS with a database is the "fuel" that accelerates these changes, especially in terms of dynamic in inserting changes and maintaining a modern cadastre. Most of the plots in Montenegro have a problem of discrepancy between data in graphic database and in alphanumeric one. In this paper due to the problems in uniformity of geodetic networks in Bar we analysed examples and offered solutions for the territory of that Municipality.

Through the procedure of parcelling the cadastral plots according to planning document there can be resolved the problem of deviations of boundaries in cadastral plots compared to the position of the existing borders on the ground provided that the drafter of the plan before making the parcelling plan is equipped with up to date and quality cadastre - topographic maps. Otherwise, accepting the cadastral defined boundaries position of real estate and topographic details eliminates the possibility of harmonizing the current situation on the field with the situation in the cadastral records.

\section{REFERENCES}

FAO Land Tenure Studies 6, The design of land consolidation project in Central and Eastern Europe", Rome, 2003.

Čvorić, D. "Komasacija kao pokretač održivog razvoja ruralnog prostora" (Land consolidation as a driving force of rural area sustainable development), Geodetska služba, Beograd 2011, pp 20-28

Đurović, R., (2011): Improving the maintenance of the state survey and real estate cadastre. Master's thesis, University of Belgrade, Faculty of Civil Engineering.

Larsson, G., (1997): Land readjustment: A tool for urban development. Habitat International, Volume 21, Issue 2, Pages 141-152, June 1997.

Longley, P., Goodchild, M., Maguire, D., Rhind, D. (2005): Geographical Information Systems; Volume 1; Principles and Technical Issues, Second Edition; John Wiley\&sons, Inc; New York; pp.358

Lukić, V., (1977): Komasacija zemljišta u SR Bosni i Hercegovini, Zagreb 
National Assembly of the Republic of Montenegro, (2007): Law on the state survey and cadastre. Podgorica: Official Gazette of the Republic of Montenegro no 29/07, 40/11.

Nikolic, R. G. (2010): Geoecological mapping of protected areas of nature in Montenegro. (Doctoral dissertation). Fond professional library Faculty of Geography in Univesity of Belgrade. pp-0-317.

Real Estate Directorate - Republic of Montenegro (2015): Rulebook on content and method for state survey of immovable properties, draft version.

Šoškić, M. (2016): "The development of new models of urban land consolidation in the function of the City", Ph.D. thesis, Faculty of Civil Engineering in Belgrade.

Trifković, M. (2001): Arrangements for rural land management, Higher Civil Engineering and Geodesy, Belgrade.

Vitikainen, A: An overview of land consolidation in Europe/ Helsinki University of Technology (Finland), 2004. 